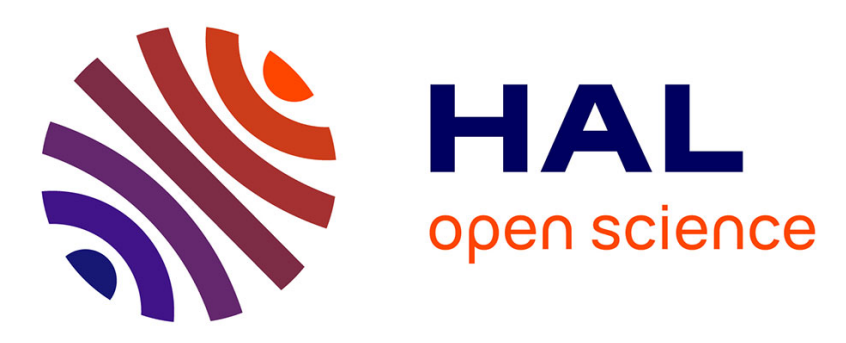

\title{
Materials Applications of an Advanced 3-Dimensional Atom Probe
}

A. Cerezo, D. Gibuoin, S. Kim, S. Sijbrandij, F. Venker, P. Warren, J. Wilde, G. Smith

\section{- To cite this version:}

A. Cerezo, D. Gibuoin, S. Kim, S. Sijbrandij, F. Venker, et al.. Materials Applications of an Advanced 3-Dimensional Atom Probe. Journal de Physique IV Proceedings, 1996, 06 (C5), pp.C5-205-C5-210. 10.1051/jp4:1996533 . jpa-00254412

\section{HAL Id: jpa-00254412 https://hal.science/jpa-00254412}

Submitted on 1 Jan 1996

HAL is a multi-disciplinary open access archive for the deposit and dissemination of scientific research documents, whether they are published or not. The documents may come from teaching and research institutions in France or abroad, or from public or private research centers.
L'archive ouverte pluridisciplinaire HAL, est destinée au dépôt et à la diffusion de documents scientifiques de niveau recherche, publiés ou non, émanant des établissements d'enseignement et de recherche français ou étrangers, des laboratoires publics ou privés. 


\title{
Materials Applications of an Advanced 3-Dimensional Atom Probe
}

\author{
A. Cerezo, D. Gibuoin, S. Kim, S.J. Sijbrandij, F.M. Venker*, P.J. Warren, J. Wilde and \\ G.D.W. Smith \\ Department of Materials, University of Oxford, Parks Road, Oxford OXI 3PH, U.K. \\ * Department of Applied Physics, University of Groningen, Nijenborgh 4, 9747 AG Groningen, \\ The Netherlands
}

\begin{abstract}
An advanced 3-dimensional atom probe system has been constructed, based on an optical positionsensitive atom probe (OPoSAP) detector with energy compensation using a reflectron lens. The multi-hit detection capability of the OPoSAP leads to significant improvements in the efficiency of the instrument over the earlier serial position-sensing system. Further gains in efficiency are obtained by using a biassed grid in front of the detector to collect secondary electrons generated when ions strike the interchannel area. The improvement in detection efficiency gives enhanced performance in the studies of ordered materials and the determination of site occupation. Energy compensation leads to a much improved mass resolution $(\mathrm{m} / \Delta \mathrm{m}=500$ full width at half maximum) making it possible to map out the 3-dimensional spatial distributions of all the elements in complex engineering alloys, even when elements lie close together in the mass spectrum. For example, in the analysis of a maraging steel, this allows separation between the ${ }^{61} \mathrm{Ni}^{2+}$ and ${ }^{92} \mathrm{Mo}^{3+}$ peaks, which are only $1 / 6$ of a mass unit apart.
\end{abstract}

\section{INTRODUCTION}

In a 3-dimensional atom probe (3DAP), the single atom sensitivity microanalysis of the atom probe is combined with position sensing, to produce an instrument which is able to map out the chemical identity and position of atoms originally present in a field-ion specimen with near atomic resolution. The first 3DAP instrument to be developed was the position-sensitive atom probe (PoSAP), which uses a detector based around a wedge-and-strip anode [1]. However, this system suffers from loss of position information when more than one ion is evaporated on a single pulse. In many materials, differences of evaporation fields between elements make it impossible to avoid multiple ion events, and in these cases quantitative analysis requires a multi-hit detector. The tomographic atom probe (TAP) uses a detector based around a $10 \times 10$ multi-anode array to provide multi-hit detection [2]. The electron cloud from each ion is divided between 4 elements in the array, and exact ion positions are calculated by charge centroiding.

The optical PoSAP (or OPoSAP) combines a primary detector (a chevron channel plate and phosphor screen assembly), a gated image-intensified camera and an anode array photomultiplier tube [3]. The arrangement of the detector system is shown in Figure 1. Light generated at the primary detector by an ion impact is divided by a partially reflecting mirror and focussed on both the camera and photomultiplier tube. The camera image of a spot on the detector provides an accurate position determination, as in the optical atom probe [4]. Light from the same spot reaching the photomultiplier produces a signal on one (or more) of the anodes, permitting approximate flight time and position measurements for the ion. Together with the accurate flight time measurement from the primary detector, this combination therefore gives parallel position determination and parallel flight time measurements for multi-hit events in the atom probe, and results in a significant improvement in positioning efficiency. The detection efficiency is also improved by including a positively biassed mesh in front of the input channel plate [5]. This causes secondary electrons generated when ions strike the area between the channels to be returned towards the detector. Detection of these electrons increases the efficiency of the detector above the open area ratio of the channel plate $(65 \%)$ to approximately $80 \%[6]$.

Previously, 3DAP instruments have been based around a straight flight path configuration, such that their mass resolution has been limited by ion energy variations to $\mathrm{m} / \Delta \mathrm{m}=100-200$ full width at half maximum (FWHM). We have built an instrument which combines an OPoSAP detector with energy compensation based on a reflectron, to produce the first energy compensated 3DAP [7]. This instrument 
makes it possible to perform 3-dimensional atomic-scale elemental mapping of complex engineering alloys which have mass peaks lying close together in the spectrum. The mass resolution which can be obtained with the instrument $(\mathrm{m} / \Delta \mathrm{m}=500 \mathrm{FWHM})$ is demonstrated in Figure 2, which shows the mass spectrum from the analysis of the stainless maraging steel, Sandvik 1RK91. Although some of the nickel and molybdenum peaks are only $1 / 6$ mass unit apart, they are fully separated.

This paper describes some of the initial applications of the new high mass resolution, high detection efficiency 3DAP to problems in materials science.

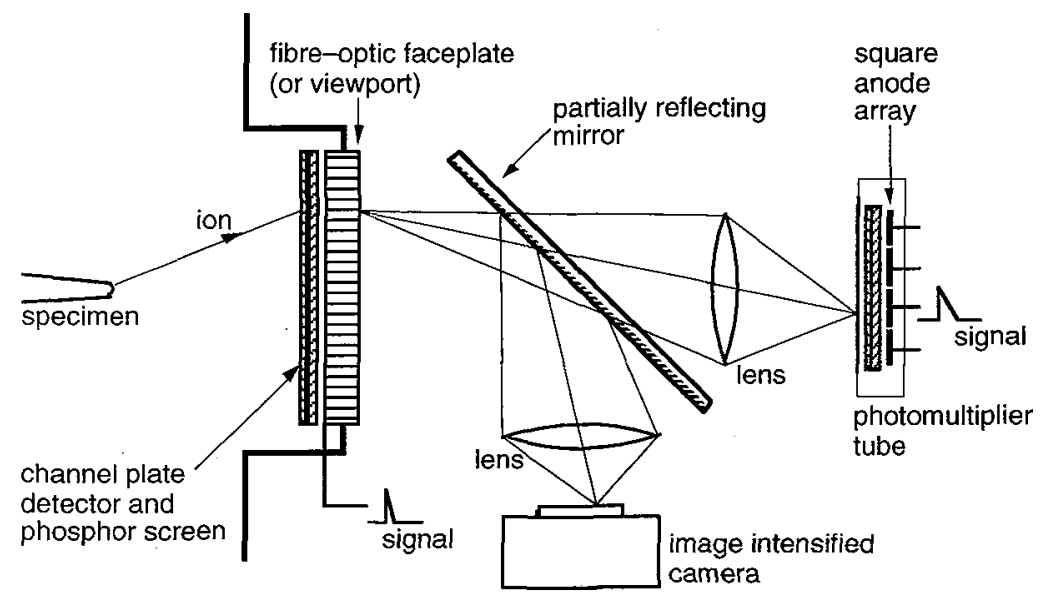

Figure 1: Schematic diagram of the optical position-sensitive atom probe (OPoSAP) detector design. (See text for full details.)

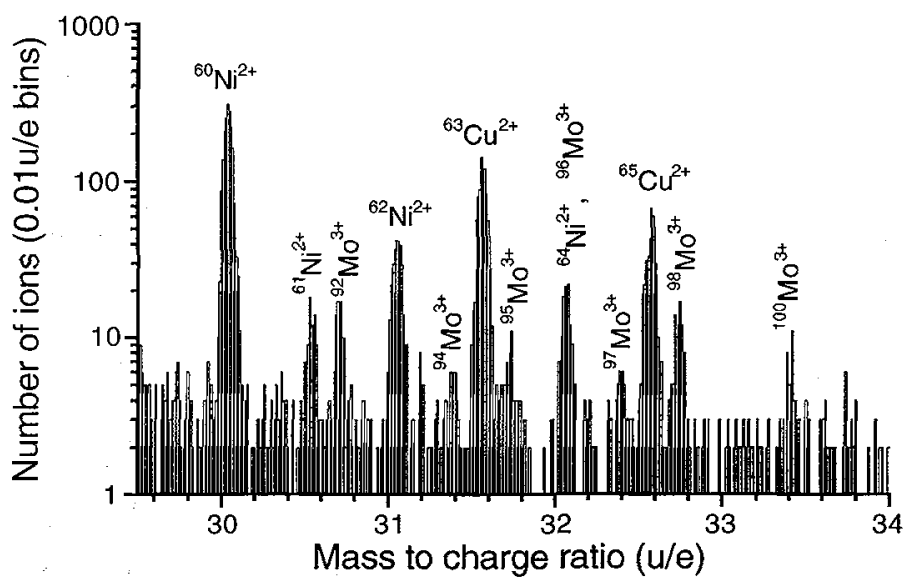

Figure 2: Mass spectrum from the analysis of the stainless maraging steel 1RK91. The mass resolution measured from the spectrum is $m / \Delta m=500$ full width at half maximum, and $m / \Delta m=500$ full width at tenth maximum.

\section{SITE OCCUPATION IN TITANIUM ALUMINIDE}

Titanium aluminide intermetallics are of interest for specific high temperature applications in, for example, jet turbines [8]. However, they suffer from significant drawbacks at present, including lack of medium temperature ductility, and environmental degradation. A range of substitutional elements are being investigated for their ability to modify the intermetallic properties and optimise the alloys for specific 
applications. In order to understand the phase stability of these intermetallics, it is important to determine the sites occupied by the substitutional elements within the ordered $\mathrm{L}_{0}$ structure [9].

A section from the OPoSAP analysis along the [001] direction of Ti-48at.\%Al-2at.\%Ru, showing the region close to the $(001)$ pole, is given in Figure 3. The depth scaling in the atomic distribution (Figure 3a) is taken directly from the sequence of detection of atoms within the entire analysis, with no depth corrections. Individual $\mathrm{Ti}$ and $\mathrm{Al}$ planes within the superlattice are clearly visible, with differences in spacing which are due to the very different evaporation fields for the two elements. An aluminium plane evaporates slowly, followed rapidly by a titanium plane, [10] so the aluminium planes appear wider than those of titanium. The positions of the ruthenium atoms is also shown, and these appear to be associated with the Al planes. This is demonstrated more clearly in the ladder diagram plot of Figure 3(b). However it should be noted that such a result can be influenced by preferential evaporation or retention, and further data is required to confirm this observation. The success of a plane-by-plane analysis such as this is critically dependent on having high detection efficiency.

a)

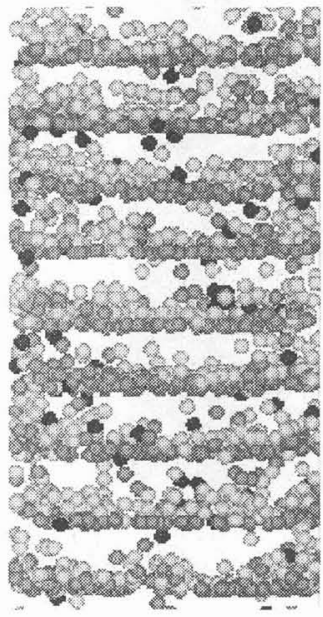

b)

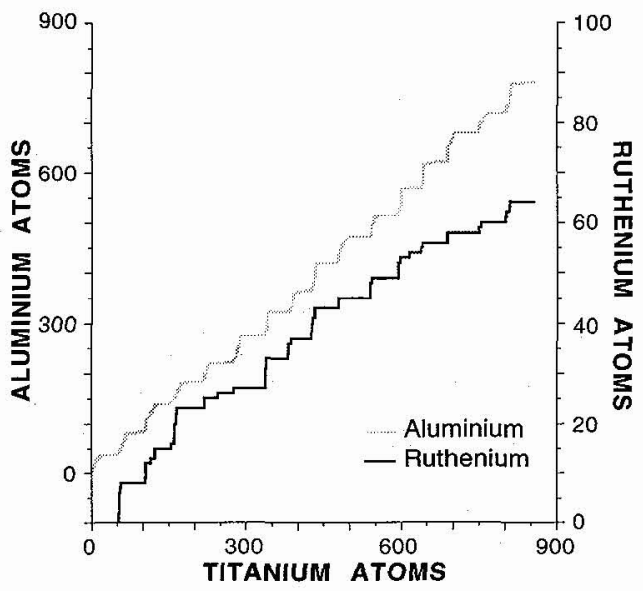

Figure 3: Optical PoSAP analysis of a Ti-48at.\%Al-2at.\%Ru intermetallic. (a) Atomic distribution (dark grey: Ti, light gray: Al, black: $\mathrm{Ru}$ ) which shows single, ordered atomic layers. (b) Ladder diagram showing the sequence of the atoms from the analysis demonstrates the ordering more clearly, and also shows the apparent location of the Ru atoms within Al planes.

\section{RHENIUM-CONTAINING NICKEL-BASED SUPERALLOY}

Superalloys continue to be the primary high temperature material for jet engine turbine blades [11]. Since their original invention in the 1950s, there have been incremental improvements in superalloy properties. The current generation of nickel-based superalloys have significant levels (5-6 wt.\%) of rhenium added, in order to improve the high temperature creep resistance. However, the exact mechanism by which this improvement occurs is not yet understood.

An OPoSAP analysis through the $\gamma / \gamma^{\prime}$ interface in a rhenium-containing nickel-based superalloy is shown in Figure 4. The alloy had been solution treated and aged at $1100^{\circ} \mathrm{C}$. Elemental distributions of nickel and aluminium clearly show the position of the interface. On the left-hand side, the aluminium concentration is low and is distributed randomly. To the right, there is a higher level of aluminium and it is clearly arranged in atomic planes, which correspond to the mixed planes in the $\mathrm{Ll}_{2}$ ordered superlattice. As in the case of the titanium aluminide intermetallic, the spacings of the superlattice planes do not appear to be equal, as the evaporation field for the mixed $\mathrm{Ni}+\mathrm{Al}$ layers is higher than that for the pure nickel. Individual atomic planes can also be discerned in the nickel distribution within the $\gamma$ phase, but this is not so clear since the spacing between planes is identical, and half that of the superlattice spacing in $\mathrm{Ni}_{3} \mathrm{Al}$. The rhenium distribution shows strong partitioning to the $\gamma$ phase, and atom probe measurements have indicated that there is an increased concentration at the $\gamma / \gamma^{\prime}$ interface, although this is not clear from the element distributions in Figure 4. This is likely to be a 'bow wave' effect generated by the rejection of rhenium from the growing $\gamma^{\prime}$ phase. The slow diffusion of rhenium during creep may be the cause of the observed improvements in properties. 


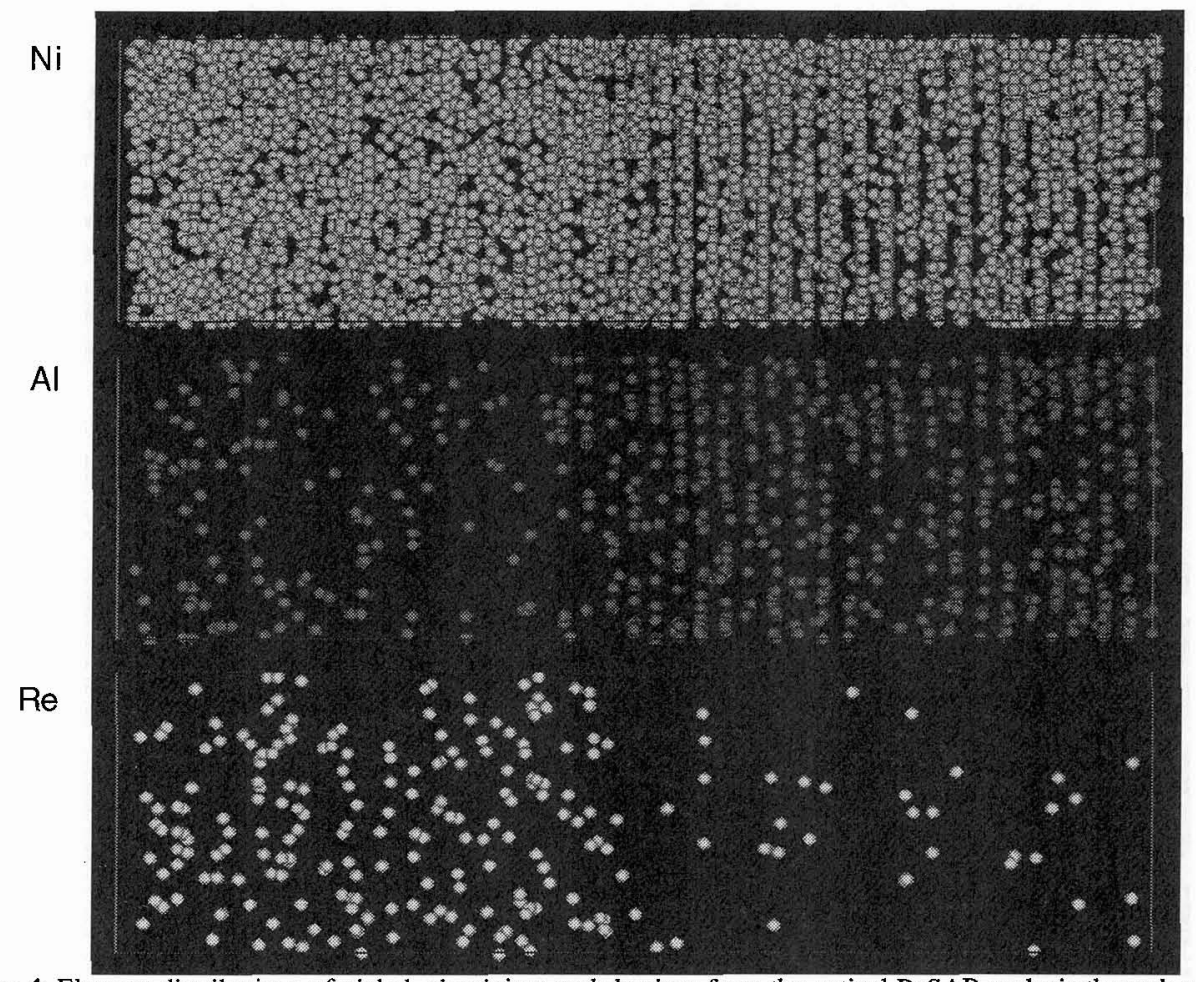

Figure 4: Element distributions of nickel, aluminium and rhenium from the optical PoSAP analysis through a $\gamma / \gamma^{\prime}$ interface in a rhenium-containing nickel-based superalloy. Analysis was performed along the [100] superlattice direction (across the page).
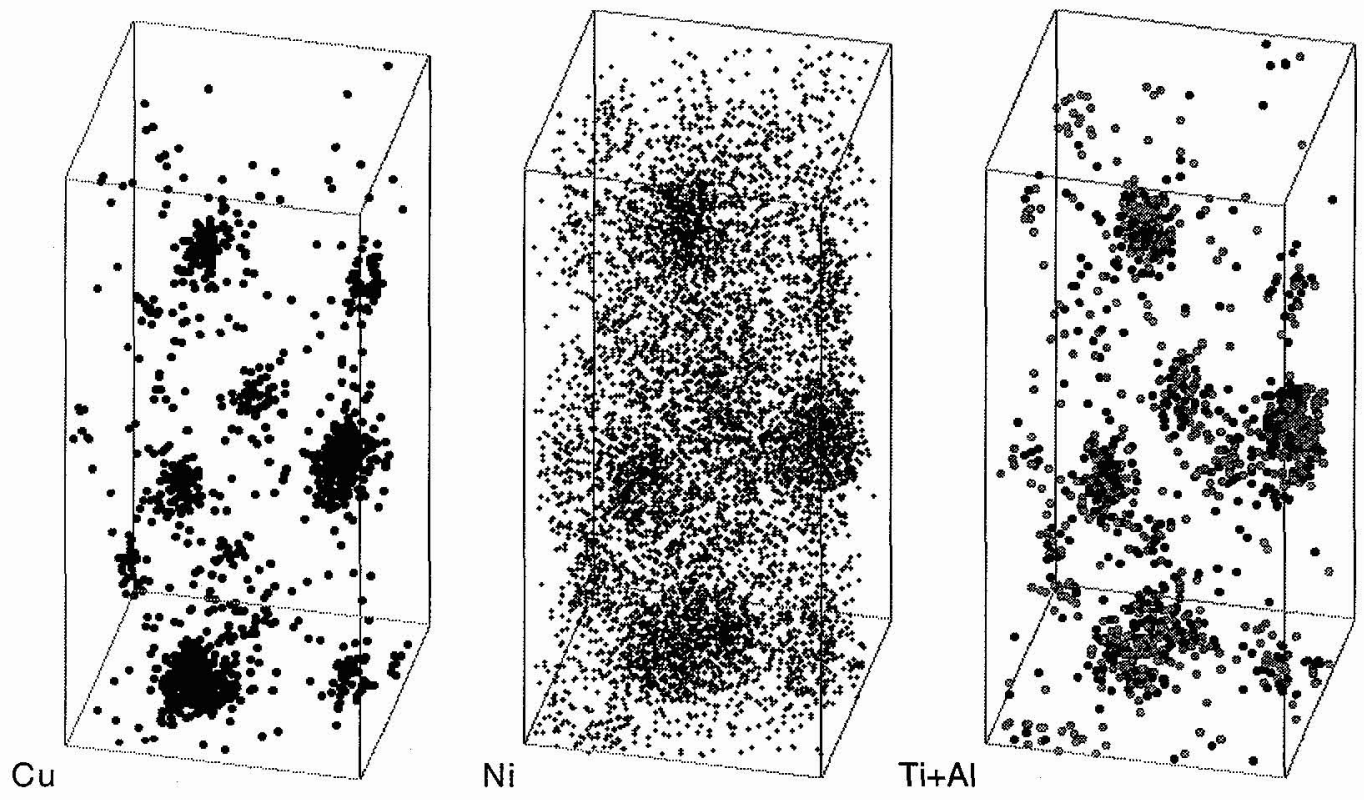

Figure 5: Element distributions for $\mathrm{Cu}, \mathrm{Ni}, \mathrm{Ti}$ (black) and $\mathrm{Al}$ (grey) from the OPoSAP analysis of Sandvik $1 \mathrm{RK} 91$ aged for 1 hour at $450^{\circ} \mathrm{C}$. Analysis volume is $6 \mathrm{~nm} \times 6 \mathrm{~nm} \times 14 \mathrm{~nm}$. 


\section{STAINLESS MARAGING STEEL SANDVIK 1RK91}

A new type of cobalt-free stainless maraging steel, Sandvik 1RK91, has recently been developed for use in surgical instruments. The steel composition is $71.6 \% \mathrm{Fe}-13.0 \% \mathrm{Cr}-8.7 \% \mathrm{Ni}-0.73 \% \mathrm{Al}-1.1 \% \mathrm{Ti}$ $1.8 \% \mathrm{Cu}-2.3 \% \mathrm{Mo}$ (at.\%). The steel is produced in wire form, hot rolled and cold drawn to $91 \%$ reduction of area, creating a fully martensitic microstructure [12]. An optimum hardness of $650 \mathrm{HV}$ and a tensile strength close to $3000 \mathrm{MPa}$ is achieved for the recommended ageing treatment of four hours at $475^{\circ} \mathrm{C}[13$, 14]. Atom probe studies of precipitation processes in this steel at $475^{\circ} \mathrm{C}$ have been reported by Stiller et al. [15], who found that $\mathrm{Ni}$ - and $\mathrm{Cu}$-rich precipitates predominated at shorter ageing times, often in contact with one another.

The OPoSAP analysis of a 1RK91 specimen aged for 1 hour at $450^{\circ} \mathrm{C}$ is shown in Figure 5. Copperrich regions form even at this early ageing, and persist throughout the ageing times studied (up to 100 hours). Adjacent to the copper rich particles, a phase is observed which is rich in nickel, titanium and aluminium. At later stages of ageing, the composition of this phase is approximately $70 \% \mathrm{Ni}-10 \% \mathrm{Al}$ $15 \% \mathrm{Ti}$, with small amounts of other elements such as $\mathrm{Cu}$. The proportions of $\mathrm{Ni}, \mathrm{Al}$ and $\mathrm{Ti}$ correspond closely to those expected for the $\gamma^{\prime}$ phase, $\mathrm{Ni}_{3}(\mathrm{Al}, \mathrm{Ti})$. Phases rich in iron and molybdenum are also observed, especially at later stages of ageing. These latter phases appear to form in contact with either the copper-rich particles or the $\gamma^{\prime}$ phase phase.

The Cu clusters shown in Figure 5 would be expected initially to have a metastable b.c.c. structure, which then transforms martensitically to the 9R structure, as in Fe-Cu alloys [16]. The lattice spacing of the close packed (009) planes of the 9R structure of $\mathrm{Cu}$ is approximately $0.204 \mathrm{~nm}$, which is intermediate between the spacings of the Fe (011) plane $(0.202 \mathrm{~nm})$ and that of the $\gamma^{\prime}(111)$ plane $(0.209 \mathrm{~nm})$. Thus as well as providing a structural template, the presence of the $\mathrm{Cu}$ particles provides for a reduction in the elastic strain energy concentration at the precipitate-matrix interface. Our observation of the $\gamma^{\prime}$ phase is at variance with the previous AEM identification of "L-phase" [7-9], and with the atom probe results of Stiller et al. [10], who report a phase with composition $48 \% \mathrm{Ni}-9 \% \mathrm{Fe}-5 \% \mathrm{Cr}-10 \% \mathrm{Mo}-19 \% \mathrm{Ti}-9 \% \mathrm{Al}$. The reason for the discrepancy is unclear, but the likely explanation is that in the previous work there was overlap of X-ray and ion signals from different phases. The high spatial and mass resolution of the OPoSAP permits a fuller characterisation of this complex microstructure.

\section{CARBON SEGREGATION TO DISLOCATIONS}

Cottrell and Bilby, in their classic work of 1949, first developed the idea that the segregation of carbon atoms to form atmospheres around dislocations could be used to describe the strain ageing in iron [17]. Using an imaging atom probe (IAP), Chang provided the first direct evidence for these 'Cottrell atmospheres' [18]. By superimposing field ion micrographs and carbon gated IAP images, Chang demonstrated carbon segregation to dislocations in low carbon lath martensites. However the efficiency for detection of carbon in the IAP was low, since carbon field evaporates in a number of cluster species and it was only possible to gate for a single species at any one time.

We have extended the work of Chang by using the OPoSAP to perform three-dimensional atomicscale mapping of carbon atmospheres at dislocations. A high purity $\mathrm{Fe}-1$ at $\% \mathrm{C}$ alloy was austenitised at $1100^{\circ} \mathrm{C}$ and rapidly quenched, first into iced brine and then into liquid nitrogen, to generate a fully martensitic structure. The lath martensite has a high density of dislocations, of the order of $10^{11}-10^{12} \mathrm{~cm}^{-2}$, increasing the chance of observing a dislocation within a given field-ion specimen. Specimens were subsequently stored at $0^{\circ} \mathrm{C}$ and then room temperature aged for varous times (in excess of 24 hours) before FIM imaging and OPoSAP analysis. Figure 6a shows a field ion micrograph from a small area of a room temperature aged $\mathrm{Fe}-1 \mathrm{at} . \% \mathrm{C}$ martensite specimen. The spiral contrast clearly the presence of a dislocation, though there is not sufficient information in the FIM image to determine its type, except that there is a component of the Burgers vector normal to the specimen surface. OPoSAP analysis of the same region clearly shows the carbon segregation associated with the dislocation, Figure $6(a, b)$, which has a distinctly anisotropic radial distribution. The atmosphere has a peak concentration of approximately 8 at. $\% \mathrm{C}$ and contains $21 \pm 1$ carbon atoms per atomic layer along the dislocation line. The high detection efficiency and high positioning efficiency of the OPoSAP is essential for accurate characterisation of these carbon atmospheres. 


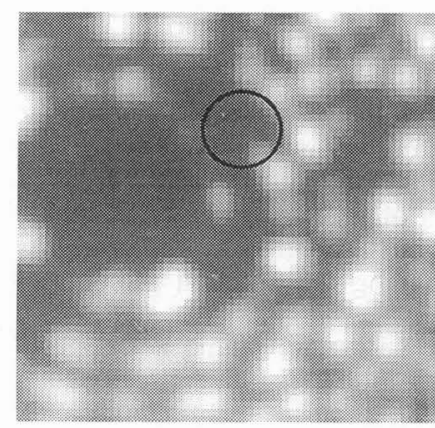

a)

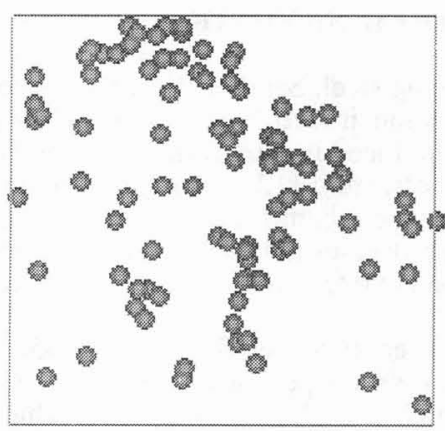

b)

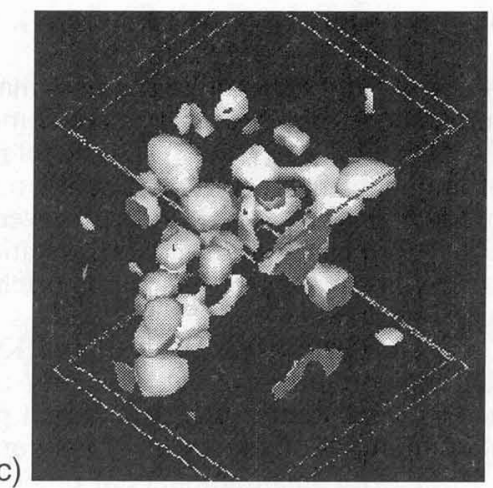

Figure 6: a) Field-ion micrograph from a room temperature aged $\mathrm{Fe}-1$ at.\% $\mathrm{C}$ martensite, demonstrating the presence of a dislocation (circled). b) Carbon distribution from the OPoSAP analysis of the same region as in (a), showing segregation around the dislocation. The image is $10 \mathrm{~nm} \times 10 \mathrm{~nm}$, and integrated over a depth of 5 atomic layers. (c) Isosurface reconstruction of the carbon distribution from the entire analysis volume (10nm x $10 \mathrm{~nm} \times 4 \mathrm{~nm})$, drawn at a level of 4 at. $\%$.

\section{Acknowledgements}

The authors would like to thank Dr. P. Liu, of A.B. Sandvik Steel R \& D Centre, Goteborg, Sweden, and Dr. R. Broomfield (Rolls-Royce) for the supply of specimen materials. We gratefully acknowledge financial support from: Engineering and Physical Sciences Research Council (SJS), Kindbrisk Limited (SJS), The Royal Society (AC and PJW) and Wolfson College, Oxford (AC). The authors are grateful to Professors B. Cantor and D.G. Pettifor for the provision of laboratory facilities. This research was supported by The Paul Instrument Fund of The Royal Society, and by the EPSRC under grant number GR/H/38485.

\section{References}

[1] Cerezo A., Godfrey T.J. and Smith G.D.W., Rev. Sci. Instrum. 59 (1988) 862-866.

[2] Blavette D., Deconihout B., Bostel A., Sarrau J.M., Bouet M. and Menand A.. Rev. Sci. Instrum. 64 (1993) 2911-2919.

[3] Cerezo A., Godfrey T.J., Hyde J.M., Sijbrandij S.J. and Smith G.D.W., Appl. Surf. Sci. 76/77 (1994) 374-381.

[4] Miller M.K., Surf. Sci. 266 (1991) 494-500.

[5] Panitz J.A. and Foesch J.A., Rev. Sci. Instrum. 47 (1976) 44-49.

[6] Sijbrandij S.J., Cerezo A., Deconihout B., Godfrey T.J. and Smith G.D.W., these Proceedings.

[7] Sijbrandij S.J., Cerezo A., Godfrey T.J. and Smith G.D.W., Appl. Surf. Sci. 94/95 (1996) 428433.

[8] Kim Y.-W., Journal of Materials, July 1994, 30-39.

[9] Wesemann J.G., Frommeyer G. and Kreuss M., Appl. Surf. Sci. 87/88 (1995) 179-184.

[10] Liu Z.G., Frommeyer G. and Kreuss M., Phil. Mag. Lett. 64 (1991) 117-124.

[11] McLean M., High Performance Materials in Aerospace (Flower H.M. ed., Chapman and Hall, London, 1995) pp. 135-154, and references therein.

[12] Holmquist M., Nilson J.-O. and Stigenberg A.H., Scripta Metall. Mater. 33 (1995) 1367-1373.

[13] Nilson J.-O, Stigenberg A.H. and Liu P., Metall. Mater. Trans. A, 25A (1994) 2225-2233.

[14] Liu P., Stigenberg A.H. and Nilson J.-O, Acta Metall. Mater. 43 (1995) 2881-2890.

[15] Stiller K., Danoix F. and Bostel A., Appl. Surf. Sci. 94/95 (1996) 326-333.

[16] Othen P.J., Jenkins M.L. and Smith G.D.W., Phil. Mag. A A70 (1994) 1-24.

[17] Cottrell A.H. and Bilby B.A., Proc. Phys. Soc. A62 (1949) 49.

[18] Chang L., Barnard S.J. and Smith G.D.W., Fundamentals of Ageing and Tempering in Bainitic and Martensitic Steel Products, G. Krauss and P.E. Repas Eds. (Iron and Steel Society, Warrendale, PA, 1992) pp. 19-28. 